DOI: 10.11606/issn.2238-3867.v16i2p273-285

sala preta

ppgac

Dossiê Sobre a Cia. Brasileira

\title{
Os nomes do ato: PROJETO bRASIL e Nós
}

The names of the act: PROJETO bRASIL and Nós

\section{Angela Mousinho Leite Lopes}

Angela Mousinho Leite Lopes

Professora Titular do Centro de Letras e Artes e colaboradora do PPG em Artes Visuais da Escola de Belas Artes da

Universidade Federal do Rio de Janeiro. Atriz e tradutora.

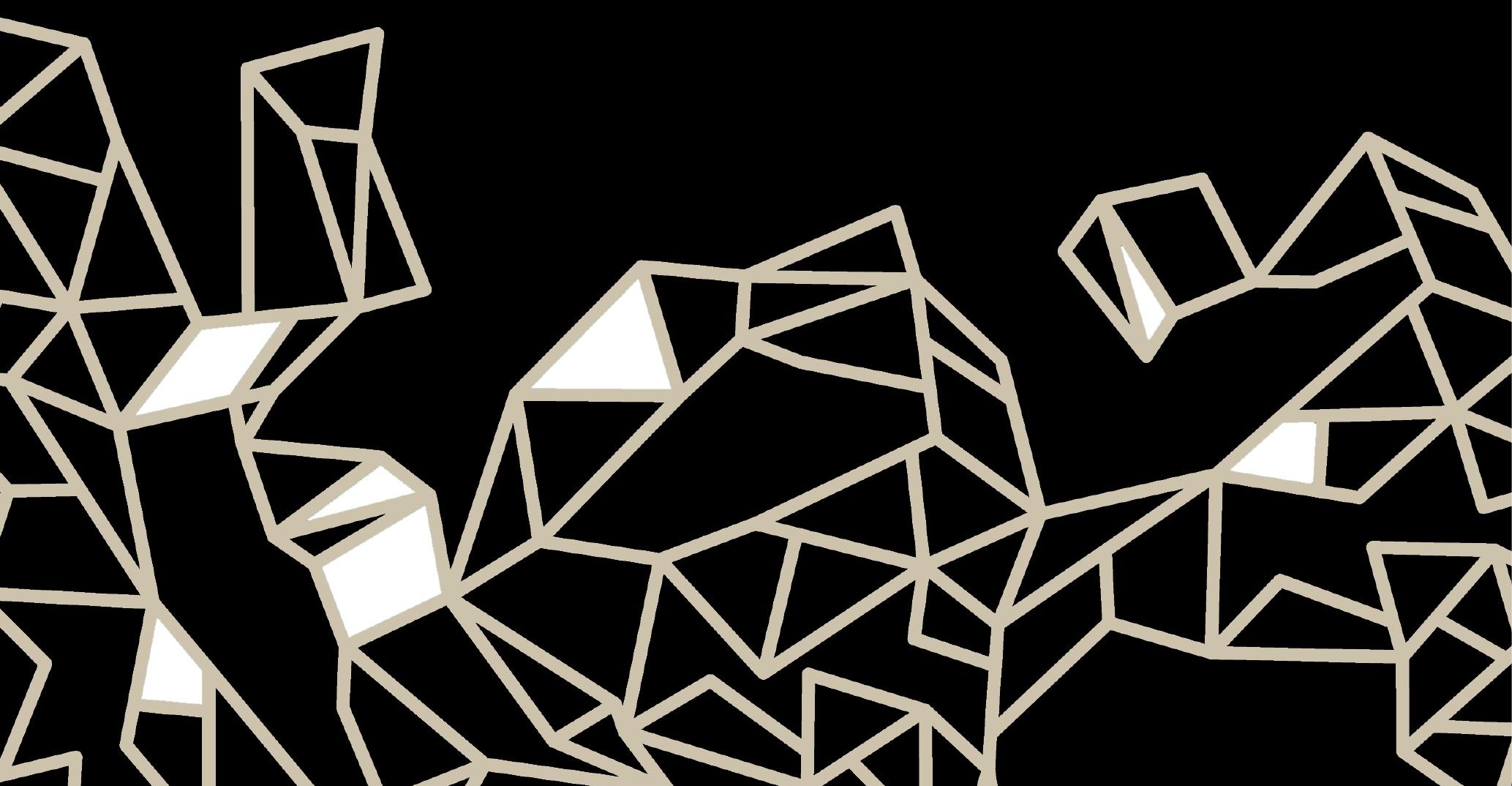




\section{Resumo}

Este artigo procura apontar, a partir da maneira como Marcio Abreu conduz a criação de PROJETO bRASIL e Nós, os rumos que o teatro está tomando neste início do século XXI, acompanhando as transformações radicais das noções de saber, imaginação, tempo e espaço que vêm dar lugar às de performance, ato e presença, voltando a valorizar a dimensão política do fazer artístico.

Palavras-chaves: Marcio Abreu, Teatro, Performance, Política.

\section{Abstract.}

Based on how Marcio Abreu leads the creation of PROJETO bRASIL and Nós, this article seeks to indicate the paths being taken by the theatre in this beginning of the $21^{\text {st }}$ century, following the radical transformations of knowledge, imagination, time, and space notions, which are now relayed by those of performance, act, and presence, bringing back the political value of art performance.

Keywords: Marcio Abreu, Theatre, Performance, Politics.

\section{Casa Branca, MG, 13/8/2016}

Quando recebi o convite para escrever este artigo, pensei que seria a oportunidade para começar a dar forma a algumas das impressões que me acompanharam após ter assistido a dois dos últimos espetáculos do Marcio Abreu: PROJETO bRASIL e Nós.

Com o pensamento à deriva nesses dias de férias, vou percebendo que o que já se delineava era também a possibilidade de ir tecendo considerações e reflexões acerca da necessidade de se repensar os nossos modos de perceber, de ensinar, de criar, num momento de radical transformação de tudo que nos configura.

Nesse primeiro momento são quase devaneios, lembranças e evocações de espetáculos os mais diversos, que vão desfiando toda uma cadeia de reminiscências e que vão formando uma espécie de embalo que vai conduzir minha escrita. 


\section{Belo Horizonte, MG, 15/8/2016}

Encontro com Marcio para conversar um pouco sobre a perspectiva de participar desse dossiê sobre ele e de escrever este texto. Relembramos rapidamente os espetáculos dele aos quais assisti. Ele me fala do ato do teatro, de seu interesse na presença como algo convivial e relacional.

Apesar de ter acompanhado boa parte da trajetória do Marcio, com a companhia brasileira de teatro e fora dela, decido escrever mesmo a partir de PROJETO bRASIL e Nós, na expectativa de que algo se desenrole a partir desses nomes.

Esses nomes não são propriamente títulos. São provocações. São atos com os quais estamos comprometidos hoje, mais do que nunca, neste mês de agosto de 2016.

Falamos desse comprometimento também nesse nosso rápido encontro. Como deixar de falar?!

\section{Rio de Janeiro, RJ, 20/8/2016}

Memória é o que mais tem sido vivido e evocado neste momento no Brasil. Estamos todos muito metidos e mexidos na nossa história. A política volta a ocupar a cena com todo um clamor novo. Ao ataque à democracia há respostas diversas e criativas por parte de vários setores da sociedade. Isso pelo menos é um alento.

Vivemos um desses momentos em que a perplexidade se traduz na dúvida se a História se repetiria. O fato é que no teatro, não. Há 50 anos, o gesto de tentativa de enfrentamento da opressão era na maioria das vezes o de reescrever a história. Hoje, substitui-se história por ato. De fato, os enredos passam a importar cada vez menos, as peças se tornam cada vez mais composições com múltiplas possibilidades de sentido, e a cena passa a ser o lugar de atos. Ou seja, o sentido passa a ser um ato executado também e sobretudo pelo espectador. A operação de criação deixa assim de ser direcionada, imposta, e passa a ser produzida tanto no palco quanto na plateia. Há aqui, portanto, um paralelo entre política e arte! Voltar a chamar atenção para os atos tem algo de resistência e de didatismo. Sabemos hoje mais do 
que nunca que histórias têm todo tipo de versão. Já os atos provocam marcas, algumas indeléveis.

Há algo aí que de fato se configura como Projeto. Pra Nós. É disso que quero falar.

\section{Política, Teatro}

Michel Serres (2013), em eu livro Polegarzinha, afirma que estamos vivendo o ocaso da era do saber. Tomo isso como uma provocação para pensar nosso momento atual. Não compartilho do temor de muita gente em relação ao mundo digital e a grande parte do que ele acarreta; pelo contrário, acho essa perspectiva de passagem de era libertadora. Como tudo que foi conquistado em nossa longa trajetória de dita civilização, o saber tem também um aspecto nitidamente hierárquico e discriminatório, embora seja, na origem, fonte e motor de liberdade e de transformação. Basta olhar para as instituições que hoje o produzem e transmitem para constatar que muitas vezes elas mais parecem ostentar esse saber que questioná-lo e reinventá-lo, demonstrando uma clara propensão para seu enrijecimento e sua mitificação. $\mathrm{O}$ saber, como toda e qualquer atividade, tem que ser colocado em xeque para que algo volte a se produzir com seu clamor inicial. $\mathrm{O}$ saber não pode se tornar um bem ou então declina, se esgota, vira fim de linha. É, portanto, o próprio motor de transformação que estava na origem do saber que passa para outra esfera. A rigor, é o próprio saber que leva a essa nova era.

Quero aqui ligar essa provocação à constatação de Pierre Francastel ([s.d.]), já citada por mim em diversas ocasiões, de que o teatro legou à civilização que termina um lugar para a imaginação. Em primeiro lugar, chamo atenção para o fato de que Francastel já falava nos anos 1960 em civilização que termina. $\mathrm{E}$ que o teatro permanece como legado: o da cena à italiana como a coincidência entre espaço real e espaço imaginário.

Todos sabemos que há uma relação estreita entre saber e imaginação. Um não pode ser desvinculado do outro. O ocaso do saber traz junto um declínio da imaginação. Isso se insinua de forma bastante nítida nos dias de hoje: basta observar as novas gerações.

Mas o que será de nós, agora, artistas ligados ao teatro? Deste que foi um dos pontos altos dessa era do saber, participando da fundação de suas 
instituições mais relevantes, como a democracia e a noção de política? O que nos resta?

\section{Atos}

Digo, talvez de forma apressada: atos. Atos em sentido bruto. Atos em sentido radical. Não os que representam. Não os que se inscrevem na instância da interpretação. Atos que desempenham. Performances.

Michel Serres (2013) arrisca um nome pra essa nova era - "procedural" (p. 85) -, mas considero que não vem ao caso se preocupar com uma nomenclatura específica. O que ele busca apontar é que estamos entrando na era dos procedimentos, do manuseio, do fazer, do desempenho. Foi a partir daí que comecei a vislumbrar a possibilidade de entendimento das proporções tomadas pelo fenômeno da performance nos últimos anos, porque Serres sugere um arcabouço mais amplo de tudo que está envolvido nessa passagem do século $X X$ para o século $X X I$. E é justamente aí que as transformações radicais no campo das artes também se originam.

Essa percepção foi importante para mim porque eu vinha intuindo que a simples utilização de novas mídias, a simples mistura dos domínios artísticos e a impregnação de todos eles pelo digital não acarretavam uma mudança estrutural, profunda e definitiva no acontecimento teatral e na noção de cena especificamente. É preciso perceber como está se dando a reviravolta das dimensões de tempo e espaço para conceber aquilo a que a performance vem se contrapor.

Se acrescentarmos à provocação de Michel Serres essa afirmação de Pierre Lévy (1993) de que "a rede não está no espaço, ela é o espaço" (p. 26), poderemos inferir que ocorre hoje uma espécie de imobilismo no que antes era movimento e experiência. Está tudo ao alcance do dedo, o que acaba eliminando boa parte do percurso que estava embutido na experiência do saber.

De fato, gosto de relembrar aos meus alunos aspectos prosaicos, mas talvez ilustrativos dessa passagem, como a rotina de um pesquisador há apenas algumas décadas: ir a uma biblioteca, procurar nas fichas catalográficas a localização do livro, anotar seus códigos e fazer o pedido. Quantas vezes vinha a resposta que o livro estava emprestado e era então preciso voltar dali 
a um tempo! Quantos deslocamentos, quanto tempo despendido e quantos acasos também! Não que essa experiência tenha sido eliminada de nossas vivências. Mas houve uma redução considerável e, sobretudo, há a perspectiva de se ter uma relação completamente diferente com a busca por qualquer tipo de informação, inclusive as mais rebuscadas e eruditas, a de se ter tudo ao alcance do dedo. E o que está em jogo nessa diferença diz em grande parte respeito à vivência espaço-temporal, que não compromete mais o corpo.

E é disso que se trata quando a performance vem se substituir à cena. Ela vem trazendo, entre outras coisas, novas maneiras de refletir sobre essa nova modalidade de vivência, colocando o foco no corpo, justamente, para fazer dele o campo do contraponto, da crítica, da criação.

Performance quer dizer desempenho e apresenta assim claramente uma nuance em relação ao happening: enquanto este se constituía como acontecimento, ou seja, um desenrolar no tempo e no espaço, a performance parece estar focada em noções como corpo e presença. Ocorre então uma nuance entre acontecimento e ato: o acontecimento enquanto desenrolar; o ato enquanto presença.

Claro que o que estou procurando apontar aqui pede e merece um desenvolvimento muito mais generoso e detalhado. São indicações de uma reflexão que pretende se estender e assim abranger a diversidade dos aspectos ali embutidos. Mas é a partir delas, e de suas implicações políticas a meu ver profundas, que gostaria de tecer minhas considerações sobre o trabalho de Marcio Abreu.

Parece-me que são justamente as relações entre corpo e ato, em suas instâncias política e social, em suas configurações de presença e convívio, que interessam ao seu universo de criação. Isso vai ficando cada vez mais claro nesses dois espetáculos.

\section{PROJETO bRASIL}

Conforme está declarado na nota que abre a edição de PROJETO bRA$S I L$, trata-se de "uma composição dramatúrgica articulada em 16 discursos verbais e não verbais, de natureza performativa, [...] criados em simultanei- 
dade com a criação do acontecimento teatral. Esta é uma estrutura aberta" (ABREU, 2016, p. 51, grifo meu).

A performance aparece então logo de início como uma conduta, reforçada pela observação quanto ao caráter em aberto da obra. Ou seja, que não se procure nenhum sentido que não seja aquele que se extrai do ato de dizer e de fazer aquilo que ali está. Poucas vezes a palavra partitura teve tanta pertinência ao ser usada para designar uma peça de teatro. Trata-se, claro, de uma advertência indispensável para o futuro leitor, aquele que não terá tido a oportunidade de assistir ao espetáculo (afinal, é para isso que textos são editados!). E, quem sabe, esse futuro leitor será um ator em busca de algo para montar... O que está apontado é, portanto, de saída, uma fricção entre a estrutura tradicional da obra dramática e a da performance.

Há também uma observação quanto à particularidade dessa peça de teatro, ou seja, dessa fatia de teatro, dessa abordagem de teatro ou qualquer outra palavra que se queira trazer para alargar o sentido de peça. Não é um texto escrito a diversas mãos ao longo dos ensaios, uma criação coletiva, como se costumava dizer. É uma peça de "natureza performativa". No meu entender: uma peça que privilegia o ato e não a narrativa, que se abstém propositalmente de narrar.

A narrativa é algo da ordem da dinâmica espaço-temporal. Por isso está tão impregnada de cena e vice-versa. Por isso mesmo, acho importante enveredar desde já pela maneira como PROJETO bRASIL se posiciona em relação a isso, ao optar por abolir totalmente o elemento narrativo do seu espetáculo. E isso vai acarretar uma condução específica da noção de cena. Vou me basear nas minhas lembranças do espetáculo, mas vou me voltar ainda neste primeiro momento para sua edição em livro, no qual está dito assim, à guisa de rubrica inicial: "preto sobre preto / espaço que sugere movimento / parede curva, sobrepalco circular que gira, sentido espiral / fim de festa" (ABREU, 2016, p. 53, grifo meu).

Quero começar chamando atenção para essa caracterização de um "espaço que sugere movimento". Não há nuance de cores, há a opção por certa circularidade. Assisti à apresentação aqui no Rio, na sala do Mezanino do Espaço SESC, em Copacabana. De um lado, a plateia, disposta em fileiras absolutamente frontais; de outro, a área de jogo, condizendo com a descrição 
citada. Essa área de jogo se prolongava numa das laterais por uma espécie de amplo vão, que tanto permitia o acesso dos atores, da coxia pra cena e vice-versa, quanto se prestava também à atuação. Mais do que um prolongamento, era uma grande abertura lateral, deixando impresso na disposição da área de jogo o caráter inconcluso da obra. Desde o início, entretanto, todas essas áreas se misturam, pois os atores circulam por entre as fileiras da plateia, saudando os espectadores, conversando, oferecendo um copinho de cachaça. Mais adiante, voltam a acorrer até o público para beijar na boca aleatoriamente de alguns dos espectadores.

Assim como em outros espetáculos de Marcio Abreu, a disposição espacial do encontro público-atores busca romper com a noção de cena. No caso de PROJETO bRASIL, o espaço sugere movimento, pois não é a dinâmica usual do teatro que está prestes a se dar. Vou contrapor aqui a movimento a noção de presença. $O$ que conduz a ação são atos autônomos. Não haverá o desenrolar de uma narrativa ou de uma ação que vá desembocar num desenlace. Como poderia, aliás, se o espetáculo se intitula PROJETO?

Num primeiro momento, claro, a ideia de projeto remete a algo que está em vias de se realizar. Algo que alude ao próprio mito do Brasil como país do futuro, como país em desenvolvimento. Mas o objeto do espetáculo é o $b R A S I L$ : tudo no título está em maiúscula, menos a inicial do nome próprio. Suspende-se assim por um momento a abstração, o conceito de nação, e opera-se no plano do concreto: brasil, matéria bruta, ato, convivialidade, presença, coisa nossa de todo dia.

Nesse sentido, é imprescindível observar como a composição da peça "em 16 discursos, verbais e não verbais, de natureza performativa" (ABREU, op. cit.) vai sendo conduzida. Não há distinção, portanto, entre agir e falar. Digo isso por se tratar de uma distinção usual no âmbito da carpintaria teatral (tradicional, o que é um pleonasmo, mas às vezes as redundâncias podem ser necessárias).

Acredito que o fato de se apontar para discursos não verbais não coloque nenhum problema. Vale a pena observar é como se dão, nesse texto, os discursos verbais. Alguns deles são objetos achados, para usar a terminologia de Tadeusz Kantor (2008), como as falas de dois políticos emblemáticos das lutas e conquistas por direitos sociais nos últimos anos, que são a ex-ministra da justiça francesa, Christiane Taubira, e o ex-presidente do Uruguai, Pepe Mujica. Faço referência a Kantor porque considero que Marcio Abreu se aproxima mui- 
tas vezes da proposta do polonês, a de tratar o texto como objeto, matéria. Isso acontece com todos os elementos da peça, aliás. Mas no caso da palavra, a ressalva é importante, pois a operação nem sempre é perceptível para o espectador desavisado. Esses discursos, retirados do contexto original em que foram proferidos, reverberam de forma muito próxima, passam a tomar a sua real dimensão política, a de ser uma fala de cada um, um ato que diz respeito a todos.

Além das falas dos políticos, há também discursos verbais que são engasgos da fala, gaguejos, não formulações de sentido pleno e imediatamente compreensível. Discursos que chamam, portanto, atenção para o ato de falar.

A fala como ato, o trabalho concreto de articular e projetar palavras, o corpo que fala: Marcio Abreu propõe uma incursão nessa dimensão fundamental da cidadania de maneira ao mesmo tempo convidativa, prazerosa, lúdica e radical. Mas de uma radicalidade suave, por assim dizer. Talvez por isso saí do espetáculo no Espaço SESC com uma sensação de desconcerto. Havia um descompasso evidente entre o desafio lançado por um certo projeto Brasil (lendo assim o título num sentido mais previsível e usual) e a sequência de atos apresentada. Um primeiro impulso me deixava com vontade de estabelecer elos e referências, de compreender o projeto de Brasil que eles encenavam. Imagens de fim de festa, de violência física, a famosa ária da Bachiana $n^{\circ} 5$ de Villa-Lobos soando enquanto o sobrepalco gira com atores em cima, tudo isso lançava pra mim um apelo de reminiscências, de imagens e evocações. E se somava à postura ativa de espectadora que era volta e meia chamada a participar, nem que fosse pelo fato de ser beijada ou de ter $\mathrm{o}$ ator ali bem perto, pedindo e oferecendo cumplicidade. Essa sensação foi se dissipando com o decorrer do tempo e foi me parecendo que a chave para entrar naquele universo estaria justamente nessa outra faceta, ali explorada, do ato artístico, sem estardalhaço e sem acabamento. Na qualidade de presença que ele requer, induz, produz. Só assim esse projeto condiz com sua proposta de estrutura em aberto. Só assim conduz a outros atos.

"Quem será o primeiro a dizer uma palavra? Quem vai tomar esse risco para si? De dizer a primeira palavra e, de repente, entender que não era o que todos esperavam, que não era a palavra exata pro momento?" (ABREU, 2016, p. 82). Assim se inicia o penúltimo discurso, o Discurso 15. A atriz começa esse discurso da cena para a plateia e depois inverte essa 
posição, posicionando-se na plateia e dirigindo sua fala pra cena. É praticamente o final da peça, que vai terminar logo a seguir, falando em fim do começo e em depois do futuro, e encerrando a sessão de PROJETO bRA$S I L$ deixando a marca do risco da palavra, do ato de falar.

\section{Nós}

Reminiscências e evocações são algumas das coisas de que mais gosto ao assistir a teatro: por exemplo, quando uma cena me traz outra à lembrança. Foi assim com a primeira sequência de Nós, com o Grupo Galpão. Ela me evocou a cena do Arlequim servidor de dois amos de Goldoni, na montagem que Giorgio Strehler criou em 1947 e que é apresentada até hoje, durante a qual Arlequim serve o jantar ao mesmo tempo para seus dois amos. A ação bastante trivial de levar pratos à mesa começa num ritmo corriqueiro e tranquilo, mas vai se acelerando, se acelerando, de tal maneira que se torna um grande número de malabarismo. A graça da cena está no fato de um desastre anunciado ter sido evitado e ter se transformado num momento de beleza pela capacidade do teatro de nos fazer ver atos prosaicos e cotidianos se tornar poesia.

No caso de Nós, a repetição e a aceleração do mote de cada personagem dentro da situação de preparar uma sopa e uma caipirinha são um primeiro momento de aproximação com a plateia, de criar suspense, ternura e muito, muito humor. Tudo junto e misturado. Algo que será belamente retomado no final do espetáculo.

Como em PROJETO bRASIL, a peça é de fato toda composta por cenas que vão se arquitetando em sequências estanques. As situações se armam e se desarmam, criando uma dinâmica muito própria que revela não um enredo, mas outra abordagem para a história: no caso, aqui, a história da sutileza e do prazer do teatro.

Há nessa opção uma homenagem implícita ao Galpão como um grupo que reúne atores que têm o domínio da atuação no sentido genuinamente circense, algo que toca sempre no próprio fundamento da arte do ator. É como se, com essa cena, ocorresse uma volta para outro lugar. Reencontra-se o primeiro Galpão dos espetáculos de rua, só que agora num ponto de equilí- 
brio que dá a perceber a convergência entre teatro e performance. Trata-se, no caso do Arlequim e do Nós, de um pequeno condensado da arte do ator: o requinte da simplicidade, pois tudo ali é transformação de gesto em ato.

Retomando noções apontadas anteriormente a propósito de PROJETO $b R A S I L$, ao ser homenageado, é o próprio Galpão que é tomado aqui como objeto achado. Em seus 34 anos de existência e de trabalho contínuo, o Galpão já deixou registrada em nosso imaginário uma marca muito particular, com seu modo de atuação entre o circense e o psicológico, com suas músicas-cantigas tocadas e entoadas por cada um deles. E é a um dos aspectos dessa marca, a de atores que trabalham juntos há três décadas, que a cena da preparação da comida e da bebida se refere. Temos ali por um lado situações de cumplicidade e de discordâncias entre pessoas muito próximas; por outro, o alto grau de afinidade de um elenco na condução dos tempos e movimentos que transformam o aparente ponto de partida de uma intriga, uma reunião de amigos, em número, atração, ato.

Assim, o título já vem trazendo essa referência, a de coletivo, que vai se ampliando a ponto de ir inserindo a plateia. Como em PROJETO bRASIL, o dispositivo cênico também propõe proximidade com o espectador. Quando o público entra no teatro, os atores também já estão na área de jogo, cumprimentando as pessoas, conversando, dando algumas recomendações, se preparando para o início da performance. Ao longo da peça, um personagem indaga sistematicamente a alguém da plateia se está precisando de ajuda. No auge da repetição e da aceleração dos preparativos para sopa e caipirinha, água espirra pra todos os lados, molhando quem está sentado nas primeiras fileiras. E no final da sessão, algumas pessoas do público são brindadas com um copo de caipirinha ou uma cumbuca de sopa, antes de haver o convite para que se venha para o palco dançar junto com os atores e participar da celebração em que se transforma o espetáculo.

Eu falava de radicalidade suave na proposta criativa de Marcio Abreu porque essa inserção da plateia no ato teatral se dá no âmbito do afeto: o de afetar todos ali presentes, o de chamar para novas modalidades de convívio ou, pelo menos, de se refletir, sensorialmente, sobre elas.

A estrutura performativa de Nós é talvez menos radical que a de PROJETO bRASIL e isso se deve, sem dúvida, ao alto grau de empatia que o Galpão 
já traz consigo. Os atos não se limitam apenas ao preparo da refeição. Há também uma longa sequência em que o personagem de Teuda Bara é expulso do recinto e do grupo para depois voltar e ser por ele reintegrado; todos voltam a ficar unidos, tão unidos a ponto de ficarem todos juntos, misturados e atados por uma longa fita adesiva que os envolve e aprisiona. Há também dois atos por assim dizer isolados, dois monólogos proferidos por ela e por Eduardo Moreira, respectivamente, ambos nus, uma espécie de canja dramática.

Mas essa ressalva não retira do espetáculo sua alçada renovadora, seu gesto vigoroso no panorama teatral da atualidade. Ela aponta claramente para o movimento inerente a tudo que é chamado de novidade: há o resquício, a reminiscência, o legado, ao mesmo tempo que há o cavar, o furar, o abalar que busca, se não subverter, pelo menos revolver a matéria que está ali previamente dada.

Em entrevistas por ocasião da estreia do espetáculo, alguns dos membros do Galpão remetem às diversas acepções que se pode emprestar ao título, inclusive a de desatar os nós. Cabe então a pergunta: o entendimento do ator como intérprete, servidor de dois amos (autor e diretor), não seria uma dessas amarras das quais Ihes é pedido aqui que se desvencilhem?

Marcio Abreu tende a assumir, dentro desse contexto, um papel que vai acabar encontrando também seu momento de reviravolta, de questionamento do próprio termo de diretor ou encenador. Mais uma vez recorro a Tadeusz Kantor, que não tinha o menor apego pelo termo encenador; só não se preocupou em encontrar um outro para colocar em seu lugar. Pra quê? Ele já ocupava um lugar visível e palpável em cena, na composição do espetáculo que se realizava concretamente diante dos olhos do espectador. Encenador é uma palavra da era da ilusão... E agora, quando o teatro está cada vez mais atrelado a ato?

\section{Rio de Janeiro, RJ, 8/9/2016}

Em algum momento esse nome há de surgir, talvez quando grande parte da força que faz esse deslocamento de nomenclatura necessário já tiver arrefecido. Por ora, a figura que o Marcio Abreu encarna à frente desses dois grupos, a companhia brasileira de teatro, o grupo dele, e o Galpão, pelo qual foi convidado, é a de um provocador, um detonador. 
E um dos aspectos detonados pelos atos que provoca é o de que a palavra não é o lugar do poder, ela é a sua condição, ela está por ele investida.

E o poder enquanto condição é algo de necessariamente transitório, construído, em movimento. Poder enquanto ato. Por isso é interessante pensar com calma nas novas modalidades de ato e performance, se vierem imbuídas da força de fazer surgir novas modalidades de composição artística e política. Sem imposição de leituras hierarquizadas, sem os impedimentos de acessos prévios consagrados. $\mathrm{Na}$ abertura de sentidos que estão por vir.

\section{Referências bibliográficas}

ABREU, M. Maré / PROJETO bRASIL. Rio de Janeiro: Cobogó, 2016.

Roteiro de uma fala. In: SMALL, D. A., OLIVEIRA, D. (Orgs.). $3^{\circ}$ encontro questão de crítica. Rio de Janeiro: 7Letras, 2016. p. 54-65.

FRANCASTEL, P. A imagem, a visão e a imaginação. Tradução de Fernando Caetano. Lisboa: Edições 70, [s.d.].

KANTOR, T. O teatro da morte. São Paulo: Perspectiva; SESC SP, 2008.

LÉVY, P. As tecnologias da inteligência. Tradução de Carlos Irineu da Costa. Rio de Janeiro: Editora 34, 1993.

LOPES, A L. Traduzindo Novarina: Cena, pintura e pensamento. Rio de Janeiro: 7Letras; Faperj. No prelo.

SERRES, M. Polegarzinha. Tradução de Jorge Bastos. Rio de Janeiro: Bertrand Brasil, 2013.

Recebido em 20/09/2016

Aprovado em 31/10/2016

Publicado em 21/12/2016 